\title{
Some Considerations of the Goal Setting and Planning Processes in Public Higher Education
}

\author{
THOMAS FLEMING**
}

\begin{abstract}
Too frequently the question of institutional purpose in higher education is unaddressed despite common agreement that it constitutes the critical core of organizational life. Resultantly, universities pursue complex programmes with little internal or external consensus on fundamental goals. This paper examines some important decision making areas in higher education and isolates a number of critical institutional variables which determine the nature of planning.
\end{abstract}

\section{RESUMÉ}

Quelques réflexions sur la sélection des objectifs et les processus de planification dans l'enseignement supérieur public

La question d'objectif institutionnel est trop souvent escamotée malgré qu'elle constitue, selon l'accord commun, le noyau critique de la vie organisationnelle. Il en résulte que les universités poursuivent des programmes complexes sans trop chercher de consensus ni interne ni externe sur les objectifs fondamentaux. Cette étude fait l'analyse de quelques domaines importants de prise de décision dans l'enseignement supérieur et isole un certain nombre de variables institutionnels critiques qui déterminent l'orientation de la planification.

\section{Introduction}

Institutions of higher education throughout the world share the common realization that there is a need to replace vague and ill-defined concepts of growth with a firmer sense of planning. The definition of institutional role and mission is, however, a complex, if not perplexing, undertaking. In fact, studies of purpose in higher learning reveal little national

* The author wishes to thank Roald Campbell and Alex Bavelas for their thoughtful advice and constructive criticism in the development of this paper.

** Assistant to the President and Vice-President at the University of Victoria and is a sessional lecturer in the Faculty of Education there. 
or international agreement on goals and considerably less concurrence on how these goals might be achieved.

Typically, statements of mission in higher education echo the well-intentioned but empty phrases of "motherhood ideals" and fail to outline clear conceptions of purpose which would provide directional signals if not operational guidelines for the organization. One sadly concludes that the malaise which surrounds the entire area of post-secondary goal setting is reflective of an "educated incapacity" to confront who we are, what we are doing and why.

Such discussions of institutional purpose provoke a set of vexing questions: What social and educational principles should be espoused in an institution's statement of mission? How can an institution sponsor a forum for debate of its mission? Can the goals of a university be clearly articulated and utilized as blueprints for action? What is the most advantageous strategy for the generation of long-term institutional objectives? Who should be involved in this process and for how long? How can long-term goals be operationalized with respect to short-term objectives? Can the effectiveness of an institution be measured and by whom? Can institutional objectives be successfully communicated to personnel within the organization and to the students and the community it serves? How can an institution develop a continuous planning capacity to achieve its stated goals and to revise its objectives according to the variables of time and changing social conditions? Is it likely that a consensus can be reached within and without the academic community on the direction of higher education? What is the interface between the goals of an institution and a university's larger social purpose? To what extent are the goals of an institution determined by the political processes within the organization? What is the social responsibility of higher learning? Does the phrase, "a community of scholars" mean any thing today?

Inquiries of this nature could continue at some length with the result that even the most tenacious investigator would be discouraged by the illusiveness of his quarry and abandon his efforts. But that is a negative view. On the other hand, perhaps there is something innately worthwhile, if not immediately fruitful, in an exercise of this magnitude and order. A more affirmative perspective holds that if a study of institutional purpose prompts serious debate on who we are and where we are going, it represents a countervailing force to the listlessness that promotes organizational drift and paralysis. An acceptance of this assumption provides at least a defensible motive for this type of activity, and, at best, the promise of considerable attention to the critical core of organizational life.

\section{A Critical Juncture in Higher Education}

In recent years, profound revisions in the political, social and economic matrix have resulted in the reduction of higher education from a preeminent place in the public mind to a position of receding significance. Changing social realities and a crisis of confidence that pervades a variety of political, social and educational organizations reflects a widespread disenchantment with ambitious institutional undertakings and an awareness of the continuous dysfunctions which plague organizational life. No longer is the public-at-large prepared to invest its confidence and resources in any institution without some voice in its operation and a greater assurance of its investment. These concerns are demonstrated 
in an obvious public militance aimed at the increased sharing of authority and decision making.

This lack of public faith has been compounded by the economic uncertainty of the 1970's and a concomitant mood of fiscal restraint. In short, there is declining government and public interest in the financing of the educational enterprise. Spiralling educational costs, the apparent failure of over a decade of attempts at educational reform, more stringent occupational requirements, the inability of education to respond to a number of social problems (poverty, unemployment, crime), and a loss of faith in educational productivity, have each contributed to this reactionary mood.

Similarly, abrupt shifts in social perspectives regarding work and leisure have overturned traditional views on education. The "live to work" Protestant Ethic has been usurped by a "work to live" philosophy which emphasizes individual rather than collective development.

Another important consideration affecting educational activities is a changed conception of time brought about largely by rapid technological advancement. Instant communication has raised expectations with respect to spontaneity in problem solving and decision making. The demand for "instant accountability" has precipitated ad hoc decision making and rationality. Unfortunately, the important reflective time proferred in the past to those who made difficult social decisions is no longer available. The acceleration of events forces educators (and decision makers) not only to be present minded but to concentrate increasingly on the future and on the nature of change itself. The often voiced accusation that institutions of higher education lack relevance may be justified, however this criticism can be directed at the range of government services and other educational agencies. New perceptions of time suggest that responses to the inquiry "Who and where are we now" may be of considerably less consequence than answers to the question "who and where will we be tomorrow?".

With respect to higher education, it is obvious that the educational cult of gigantism and the "academic bull-market" that is sponsored in the last decade have been replaced with more modest community support of higher learning. While the exact focus and extent of the public's new expectations remain unclear, what is more discernible is that overalloverall perspectives regarding the value and the emphases of post-secondary education have substantially changed. (This is evidenced by the burgeoning government support for technical and applied education.)

Several trends may be anticipated. The twin demographic factors of a declining birthrate and the decreasing size of the college-age population may reduce or stabilize university enrollments ${ }^{1}$. As might be expected, the significance of the academy relative to the society it serves may be diminished - higher education will recede from the forefront of public consciousness through a loss in numbers. Universities will also face an internal problem with demographics. The widespread recruitment of young faculty members to staff institutions in the expansionary 1960's has two important and closely related implications. The first of these concerns aging ${ }^{2}$. Because of the relatively young age of many faculty members (twenty-five to thirty-five years of age) appointed during the last decade, it is statistically foreseeable that few major additions to the teaching ranks will be made until the 1990's. This forecast, of course, raises some thorny questions in connection with the current commitment to the costly training of academic specialists in graduate schools. Alternatively, the lack of turnover in instructional personnel suggests an 
increasingly serious question, how will schools of higher learning sponsor institutional revitalization in a stable and maturing situation?

Although universities will generally occupy a less prominent place in the public mind, occupational saturation in an array of general and special skill areas will continue to prompt resolute examinations of the university's capability to provide relevant and marketable career preparation. Resultantly, one can anticipate public and government attention given largely to the vocational and technical realm of post-secondary education. This likelihood will have obvious ramifications for higher learning in terms of funding for existing and developing programmes.

The emphasis on technical training clearly indicates that universities are now considered as only one of a growing number of post-secondary options. No longer are institutions of higher education heralded as the most logical and natural consequence to the completion of secondary schooling. This is explainable in part by the fact that a minor status revolt has occurred. Today university certification is not considered as a mandatory middle-class credential nor as a passport to affluence. As the national mind continues to be rivetted to the issue of unemployment, the social currency of technical and practical skills increases.

Changing perspectives toward the uses and value of academic training are visible in other areas. The manifest sense of urgency that accompanied student interest in admission to higher learning during the 1960 's has waned markedly. For the most part, there appears to be a less pressured social atmosphere toward university enrollement and considerably less emphasis on completing degree requirements in specific periods of time (four years for a B.A.). Today, student interest has shifted measurably to programmes that are practical and flexible. This movement is evidenced by both a burgeoning support of continuing and part-time educational offerings and by student receptiveness to cooperative ventures which combine theoretical and experiential education.

Taken collectively, these trends suggest the probability of dramatic revisions in the nature of higher education in forthcoming years. Moreover, the future quality of institutional life will largely relate to the organization's present ability to appropriately respond to these exacting social forces. In short, the implicit faith in the social benefits of higher education which once characterized the public's view of universities has been challenged by a pragmatic curiosity on the purpose and use of such institutions. If for no other motive than survival, this external pressure should provide the necessary impetus for investigations of institutional function and purpose.

\section{Function and Purpose in Higher Education}

While individual institutions differ in curricular emphasis, it is generally held that academies of higher learning fulfill four broad functions ${ }^{3}$, two of these are educational in nature and two are socially oriented. The first of these functions is educational and concerns the creation of new knowledge and its incorporation into the existing body of knowledge, perhaps the most obvious and most commonly shared role of universities. The second educational function of institutions of higher learning is the responsibility for the transmission of this information to a new generation. This undertaking involves both an obligation to foster learning in the general or cultural sense - what is often referred to as education - and to provide instruction in expert knowledge - what is more 
specifically referred to as training. Interwoven into this function are the notions of selection and certification. The third function is socially motivated and relates to the generation and application of knowledge to solve practical problems. ${ }^{4}$ This is the "service" role of the university. Finally, schools of higher learning perform the social task of directly or indirectly socializing the young. In recent years another social function may be included in this list. Since the democratization of higher education in the post-1945 era, universities have frequently served as custodial or delay agencies in terms of manpower supply and demand. Government policies on financial aid to students and the elongation of the individual's educational life have made it possible to forecast, if not dictate, the population of young adults entering the labor force. Thus, as industrial life is governed by the nature of the enterprise (product), the academic enterprise is determined by the performance of certain functions. These functions can normally be said to represent the products (training and certification) and the processes (enculturation and socialization) of higher education.

What, then, is the relationship between the functions of a public university in society and the institution's purpose? In simple terms, the functions of an organization describe what it does (its activities or programmes). Purpose describes what it wants to do. It can be argued, however, that these terms are totally interrelated since purpose can either issue from function or, conversely, determine it. Since the matter at hand concerns the charting of institutional direction, the important question to raise is whether or not there is consistency between the idea of the university (its purpose) and the functions of the university (as represented in its programmes).

Institutional purpose can be studied at two discrete levels - by the organization's mission, and by its goals. (Goals can be further divided to include objectives at a variety of levels.) Organizational mission ordinarily refers to the idea of the institution, that is, the global sense of purpose which it wishes to represent. Usually, statements of mission are of an "umbrella" nature in that they simply indicate a commitment to certain universally held ideals and rarely attempt to outline how these ideals might be reached. Such declarations uphold the public and academic image of the institution by their embodiment of humanistic and altruistic principles and accept the organization's responsibility to provide educational leadership and social imagination within the community. Mission is generally too vague a concept to be of use in definitions of organizational purpose.

Organizational goals more accurately describe the long- and short-term aims of a particular agency according to time. In other words, goals are broad directional aids which suggest where an institution is going and what it is doing to get there. By definition they reflect organizational policies and priorities. Objectives, on the other hand, are signposts or targets which serve as specific measures to determine whether or not progress is being made toward the larger ends (goals).

Goals in higher education can be divided into two realms - those that are stated primarily in educational terms and those that refer to the institution's "social contract". The former broadly include such goals as: excellence in the pursuit of knowledge, the development of a depth and order to learning, the cultivation of an intellectual orientation (attitudes of the mind), the provision of an experience by which students may acquire knowledge and skills to enable them to live a personally satisfying life, and, the furnishing of training in specific areas.

The second type of goals concern the social, cultural and applied ends of higher 
education. In the main, these goals include: the application of knowledge for social needs (the provision of expertise and technology for business, industry and government), the sponsorship of social events of broad community interest, leadership in general culture, the conservation of a cultural heritage and a depository for knowledge, and, the provision of a forum for discussion.

Before turning to some of the difficulties in goal setting, several observaitons should be noted with respect to the peculiar organizational nature of institutions of higher learning. In recent years it has been suggested that these institutions can be classified as "organized anarchies" because they exhibit a number of diffuse and confusing behaviors, namely: that they are inconsistent, vague and often incoherent with respect to their operational preferences, that procedures are frequently established on a trial and error basis, and that there is a considerable turnover in individual participants and an appreciable variance among individuals regarding their levels of participation. ${ }^{5}$

Unfortunately, it appears that in most institutions of higher education concepts of mission and goals are used interchangeably with the result that statements of goals are at best hazy utterances. ${ }^{6}$ Rarely are goals framed in a manner that indicate organizational emphases or direction. The causes for this confusion lie within and without institutes of higher education. It must be first recognized that it is an extremely difficult task to identify or to assign priorities to the goals of modern higher learning. To begin with, few educational goals can be stated in precise terms. Added to this there are immense uncertainties which relate to the assessment of academic performance. Moreover, as the aspirations of the community it serves, the aims of the individual scholar may be at variance with the organizational needs and desires of the university in which he resides. Thus, goal statements must not only reflect a concilliation between the institution and its social responsibility, but also between the individual and the institution. The differences which inevitably exist between these extremes and the efforts required to produce even a minor consensus makes goal definition most difficult.

Much of the ambiguity that exists with respect to goal definition and governance issues largely from the confusing relationship between external and internal authorities in postsecondary education. Because this level of education is publicly funded, its purposes are decided both in the political and educational realms. The political dimension invariably involves the attitudes and perspectives of the party in power, its leadership, and its perceptions of the needs and wishes of the body politic and special interest groups (other political parties, professional associations and the like). Thus, decision making with regard to the purpose(s) and direction(s) of higher learning is rationalized on a political as well as an educational basis. In addition to the policy positions of elected representatives, the definition of purpose has special reference to the appointed officials of state or provincial departments of education or to coordinating agencies established to administer university affairs. The manner in which these individuals perceive their roles in reflecting and interpreting public sentiment is of critical significance. While governments undoubtedly represent the major force in shaping public education at other levels, their input in the establishment of goals for higher education and their leadership in this area may be indeterminate. Consequently, the important question of who should provide leadership is generally unsettled. Furthermore, although community expectations remain high for centers of higher education, these expectations are rarely communicated to universities 
in any clear fashion. What this means is that, unassisted, it is a major undertaking for a university to sort through and evaluate the pluralistic demands made upon its services by a host of social, political and economic forces. Resultantly, the energies of public higher education are dissipated in attempting to interpret this broad range of social signals in an effort to ascertain needs. ${ }^{7}$ Briefly then, the university is indeed a "remarkable" organization in that it pursues complex programmes with little external or internal agreement about its fundamental purposes. ${ }^{8}$

\section{Goal Setting}

Despite the confusion that surrounds goal definition, it is clear that to be effective the goal setting process must order the external and internal activities and responsibilities of the institution so that levels of decision making can be identified and understood. This is largely a five-part process:

1) Overall social goals and emphases must be deduced and analyzed and result in some broad statement of the organization's mission (as aforementioned, it is unlikely that this statement of purpose can be operationalized because of its universality; however, it might well give direction to more specific goals).

2) The relationship of the university to the society it serves must be delineated to permit the organization to accurately assess its obligations and to construct goals which reflect this social contract. In other words, goals (or objectives) must be sufficiently specific so that the institution can evidence fulfillment of government and public expectations. Not only are universities ordinarily unclear in their community relationships but the swirl of the social tableau and abrupt revisions in public policy (and changes in government) undercut much-needed continuity and rapport. Furthermore, articulation rarely exists - in this case at the provincial level - on the relational nature of universities to other post-secondary institutes and centers of learning.

3) Educational and other goals must refer to the institution's curricular emphasis and organizational structure. This level of goal setting is typically beset by a myriad of internal problems. Conflicts arise in deciding what are appropriate goals, who should define them and in what manner, and what programmatic mix will maximize the institution's success. It is at this level of decision making that the university must unequivocally come to terms with its conception of itself, what it wants to be and how this can be achieved. To define its goals and identity, the institution must examine its "possible futures" and make critical decisions in such areas as: the grow th of graduate and professional schools, the weighting of graduate and undergraduate enrollment, programme emphasis, the allocation of resources, the importance of research and teaching, and, to what extent and in what areas the university will involve itself in community "service" activities.

4) The goals which relate to internal operations must be specified. This level of decision making involves the development of policies to support the organization's intent and the framing of more specific objectives to assess the institution's performance in achieving its goals. At this level decisions must be made on such issues as standards for faculty promotion and tenure, student admission, grading and the role and extent of support services. 
5) Some congruence in goals must be established between the individuals who work in or attend the institution and the aims of the institution itself. In this respect, consistency would normally be secured through the establishment of faculty and student committees in various areas of university activity and through faculty and student representation at the decision making levels of university government.

The internal goal setting process raises two central and critical questions with regard to decision making: who is most instrumental in determining the goals of the institution and, at what level does this occur (as aforementioned, the role of government and the public in the external definition of goals is unclear)? While university administrations allocate resources and exercise some obvious influence in policy areas, ${ }^{9}$ the identity of any school of higher learning is fundamentally rooted in its curriculum. In this regard, the locus of power resides with deans and faculty members at the departmental level for it is here that key decisions are made concerning course offerings and programme emphasis. It should further be noted that the loyalty of scholars is often first directed toward their discipline, then toward their colleagues and lastly toward the institution - this has serious implication for organizational goals. Moreover, individual faculty and their departmental representatives or chairmen list candidates for appointments and establish criteria for such. Clearly, recruitment is another significant element in the development of organizational identity. One additional point can be made: since government agencies for research funding grant support chiefly on the basis of individual projects, it is therefore instructional personnel who determine not only the teaching role of the institution, which might be expected, but also its research thrust. The failure of faculty members to enunciate goals other than ones which directly apply to their immediate responsibilities (teaching and research) remains a persistent impediment to the goal setting process throughout institutions of higher education.

\section{Planning}

If goals can be said to represent where the institution wants to go, then planning is the method by which it proceeds towards those ends. Unfortunately, the planning process in many universities is beset with numerous difficulties, many of which reflect the peculiar idiosyncracies of academic organizations. A number of these common problems can be readily identified. The first of these concerns goal definition and the persistent difficulty of achieving a consensus within university communities on statements of broad institutional aims, much less the strategies for realizing them. And, while administrators in general, and chief executives in particular, accept as an organizational principle the notion that leadership is responsible primarily for charting organizational direction (establishing goals), this point of view ordinarily presumes that some clarity already exists on the part of the organization with respect to its purpose. As a general rule, this is rarely the case in academic life. Unlike the private sector where the technology of an organization will describe, if not dictate, its goals, a university normally operates without such clear-cut conceptions. This overall lack of direction obviously undermines efforts at planning for the future.

A second major difficulty relates to discontinuity in university administration and the sporadic participation of faculty members in the decision making and planning processes. 
To begin with, it is significant to note that although boards of trustees are ultimately charged with academic governance, the administration of an institution is essentially the task of the chief executive. For the most part, trustees overwhelmingly direct their energies toward the maintenance of sound fiscal policies and refrain from participating in institutional planning, other than providing reactions to the ideas of their executives. The fact that there is an impressive turnover of senior university officers and that newly appointed executives exhibit a natural disposition toward generating their own plans for institutional development rather than pursuing the plans conceived by others, notably those of their predecessors, severely constrains an institution's capability to maintain a continuous planning function. In fact, chief executives pride themselves on their abilities to "turn an institution around" and generally express little interest in promoting the ideas of the past. Coupled with these administrative inclinations, there is the serious matter of fluidity in faculty involvement. Beyond the fundamental and ever-present difficulty of securing faculty enthusiasm for planning, a function that many faculty members consider to be an administrative task, there remains the problem of ensuring that faculty participation is representative of the larger academic body and that faculty will be prepared to volunteer the time necessary to complete specific planning assignments. Invariably, academics are forced to choose between their disciplinary and institutional commitments.

Despite widespread agreement on the need for comprehensive planning (and the intrinsic value of the planning process), little comprehensive planning is actually done. One can generalize that few institutions are successful in developing a planning sophistication which transcends the capital/physical plant budget variety. Other types of planning such as academic or research planning tends to become mired in the uncertainty surrounding institutional purpose or in the rivalry among academic departments for resources. Academic planning undertaken at the departmental level typically is of a "best of all possible worlds" nature, with little thought given to the decision making which might issue from this planning, the priorities of the wider organization or the level of support that is possible.

The proliferation of provincial and state-wide legislatively-empowered governing boards for publicly-funded institutions of higher education over the last two decades dramatically attests to a public and governmental concern regarding traditional modes of academic planning and resource rationalization. It has become customary for these boards to demand detailed fiscal and academic plans for institutional developments and, in a number of instances, these demands have compelled universities to reexamine previous planning practices. However, it should be underscored that while these agencies have sponsored a climate more conducive to planning, government reluctance to commit funding for periods longer than a year has proved to be a major impediment to effective planning.

In turning to a more specific discussion of planning, it should be noted that with respect to time there are essentially two types of plans - short-term and long-term. The former concerns both tactics to bring about immediate objectives - the pursuit of short-term aims - and contingency planning - "what will we do if this occurs and how will we do it?" Short-term planning appears to be most effective in an organization where considerable power is consolidated at the top. On the other hand, long-term planning relates to the pursuit of objectives over an extended period of time such as three or five years (in some organizations this time frame may be extended from ten to twenty years). As a rule, this type of planning is tempered by the realization that changing conditions necessitate a 
change in strategies. Thus, long-range planning tends to be a more continuous method and more open to inputs from members at a variety of levels within and without the organization. In all organizations there is an on-going need to reconcile short- and long-term planning procedures and the goals they represent.

In the corporate and industrial environment, three principal modes of planning exist. In the first of these approaches, top management decides in authoritarian fashion what plans should be implemented to achieve what goals. Their decisions are then passed down and enacted by the organization. The second mode might be described as the "Best Guess" method in which some form of market research is employed to forecast conditions at a particular time and predict the effects of these conditions on the organization. The last type of planning can be described as the "Ideal" or "Forget the World" method. Planning of this nature forcusses almost entirely on the internal operations of the organization. This model assumes that demands for the organization's services will continue and thereby concentrates on generating responses to the questions, "What do we do well, and how can we do it better"?

Both the "Best Guess" and "Forget the World" modes of planning are applicable to higher education. (While the essentially democratic structure of governance in modern higher education rules out the authoritarian model as an alternative, it should be noted that executive action remains a force of consequence.) $)^{10}$ The former is obviously highly reliant on the fine blend of painstaking and imaginative labors that comprise social forecasting. Suffice to say that "best guessing" is an approach filled with considerable uncertainty. The singular advantage to the latter model is that it greatly reduces the number of uncontrollable variables. By "forgetting the world", an organization can more intensely examine its own operation without the interference of external pressures. This approach has value in that it suggests a starting-point in the ordering of priorities and in its promotion of the identification of institutional strengths. Nonetheless, it should be remembered that forces outside the organization will perpetually intrude and will necessitate attention.

Ideally, the planning/goal-setting process in higher education should include the following: the provision of procedures within the institution to provide "appropriate" participation in the framing of long-term goals (these goals can then be studies and developed according to organizational capabilities); the establishment of functional objectives for all academic and administrative components and the communication of these throughout the organization; the development of a plan of action to reflect agreement on specific goals and objectives; and, the implementation of a systematic review to evaluate all goals and plans.

For educational planning to be successful, it must be aware of its own limitations and, it should not sponsor, to paraphrase Nietzsche, "the advancement of learning at the expense of man". Thus, planning in higher education should reflect human and educational principles and goals rather than the requirements of systems and technology. In other words, planning should accomplish more than the maintenance of established organizational procedures and methods. Its primary intent or focus should be educational. Effective planning is an extremely difficult task for a number of reasons. To begin with, educational purposes tend to be diffuse and interest groups compete for the establishment of goals. Secondly, the range of courses offered in higher education is greater than at any other 
level of educational endeavour. Thirdly, the organization of post-secondary institutions tends to be more complex and varied than in other systems. Additionally, higher learning does not readily lend itself to quantification (cost-benefit, cost-effectiveness) - this factor alone creates serious problems in terms of management information. Another difficulty occurs in that the "products" of higher education are aimed in part at meeting social and industrial demands in a range of areas, at a variety of levels, and according to changing needs over time.

The subject of planning raises a number of fundamental questions. Among the most significant are the following: What are the effects of external forces on the internal life of the organization? How can the need to plan and evaluate a costly enterprise like higher education be reconciled with the essential freedom of the institution? Stated in somewhat more philosophic terms, how can the need for efficiency and effectiveness be reconciled with the idea of democracy? To what extent can business methods be applied to educational planning? Can the underlying concepts of planning be linked to a philosophy of education within an institution? How does planning - normally held to be a highly rational and logical process - relate to policy making - a process which is primarily political? How can traditionally diffuse and disorganized patterns of decision making be made more efficient? How realistic is planning when applied to education? Certainly these are important questions which require satisfactory answers.

\section{Critical Variables in Goal Setting and Planning}

In planning the goals of higher education, an important variable is the question of institutional size. A decision on this matter will automatically impose restrictions on a host of other variables and thus limit the extent of the decision making process. In short, it is the decision which will have a profound ripple effect throughout the organization. The establishment of an enrollment ceiling, or of a growth rate, will imply that the institution has made a number of key decisions on such related issues as the social responsibility of the university, quality versus quantity, whether or not the enterprise will be residential or cosmopolitan, what clientele will be served, the organizational position on the principle of equality of educational opportunity (access), and the design of policy to perpetuate institutional renewal in a static situation. More directly, its effects will be seen in hiring and admission policies, curricular specialization and emphases, the structure of the academic year (scheduling), scholarly interchange and the growth of the physical plant. Most importantly, it will directly determine the level of public funding.

Another significant variable is curricular emphases or the range of courses and degrees offered by the institution. Decision making in this area subsumes a number of critical decisions in related areas such as: the desired graduate/undergraduate student ratio, the mix of full-and part-time students, the relative merits of graduate and professional schools and their relationships and respective positions in the institution, the growth rates of departments and faculties, the allocation of resources, community interests and obligations, relationships with government, specialization based on natural advantage and existing talents, and, library facilities. By definition, decisions on composition will suggest the complexion of the institution and will imply its goals and identity. 
A third major variable to be considered is the historical background of the institution. Much of the institution's thrust is understandable in terms of its past. The circumstances surrounding the organization's establishment and development, its patterns of growth, recruitment of faculty and students, relationship with the community, lines of organization, expectations of itself, and its traditions are all of major consequence in the goal-setting process. Stated differently, an examination of the roots of the institution will likely reveal not only how the institution perceives itself but will similarly suggest its priorities, the latitude that exists for change, and the constituencies both inside and outside the organization that must be considered.

Lastly, the variable of funding should be considered, although one could question to what extent this is a variable in public higher education today since funding formulas largely determine university budgets. Still, in public universities certain fiscal "unknowns" remain significant, including government support for new and proposed programmes, grants for additions to the physical plant, national policies on the financing of research, the "richness" of research grants held by faculty, and the contractual or consultative links that the university maintains with business and industry. Understandably, both levels of funding and particular funding combinations are direct and indirect influences in determining what an institution can do and how it can do it.

Above all, the goal setting process underscores the need for greater rationality in higher education by posing the questions, Where are we going, how, and why? It is an instructive process not in that it presents us with a prescription of universal principles - which it does not - but in that it hopefully provides us with a clearer vision of the present and alerts us to the unquestionable dangers of "backing into the future".

\section{FOOTNOTES}

1. The enrollment decline which would normally occur due to the decrease in size of the college-age population may well be offset by the increased participation of adults in continuing education programmes. Furthermore, some evidence exists which suggests that as job opportunities shrink, postsecondary enrollment rises.

2. Some of the implications of aging in institutions of higher learning are discussed in Max von Zur Muehlen, The New "Crises" of Canadian Universities and unpublished 3rd draft, Ottawa: Statistics Canada, 1977.

3. For an interesting discussion of these functions and for a provocative commentary on the role of science in higher education see Carl Kaysen, The Higher Learning, the Universities and the Public (Princeton, N.J.: Princeton University Press), 1969. An incisive treatment of the confusion surrounding the functions of higher education is found in Robert M. Hutchins The Higher Learning in America (New Haven: Yale University Press), 1936.

4. Historically, this function has North American roots as far back as the land-grant colleges of the 1860 's.

5. Michael D. Cohen and James G. March, Leadership and Ambiguity - The American College President (San Francisco: McGraw Hill), 1974, p. 3.

6. Typically, this is exemplified in institutional goal descriptions which are included as introductory remarks in University Calendars.

7. In recent years an appreciable number of institutions of higher learning have increasingly relied upon devices such as the Institutional Goals Inventory, (Educational Testing Service, Princeton: N.J.) to assist them in goal definition. 
45 Goal Setting and Planning Processes in Public Higher Education

8. Theodore Caplow and Reece J. McGee, The Academic Marketplace (Garden City, N.Y.: Doubleday and Company), 1965, p. 2.

9. As Cohen and March point out in Leadership and Ambiguity, the power of the chief executive (president) is modest with respect to the governance of university decision-making and institutional direction.

10. J. Victor Baldridge, "Images of the Future and Organizational Change: The Case of New York University", Academic Governance, Berkeley: McCutchan Publishing Company, 1971. 